\title{
Structure and conformational dynamics of an aromatic sulfonamide: NMR, X-Ray and computational studies
}

\author{
Stefano Menichetti, ${ }^{* a}$ Chiara Biagioli, ${ }^{a}$ Caterina Viglianisi, ${ }^{a}$ Lorenzo Tofani, ${ }^{\text {a }}$ \\ Lodovico Lunazzi, ${ }^{b}$ Michele Mancinelli, ${ }^{b}$ and Andrea Mazzanti*b \\ Department of Chemistry "U. Schiff”, University of Firenze, \\ Via della Lastruccia 3-13, 50019 Sesto Fiorentino, Italy \\ Department of Industrial Chemistry "Toso Montanari”, University of Bologna, \\ Viale Risorgimento 4, 40136 Bologna, Italy. \\ E-mail: andrea.mazzanti@unibo.it; stefano.menichetti@unifi.it
}

\section{Dedicated to Professor Manfred Schlosser in honor of his scientific achievements}

\section{DOI: http://dx.doi.org/10.3998/ark.5550190.p008.974}

\begin{abstract}
Two conformational diastereoisomers due to the hindered Aryl- $\mathrm{NSO}_{2}$ rotation were observed by NMR in the model compound $N, N^{\prime}$-bis-tosyl- $N, N^{\prime}$-dipropargyl-1,4-diamine-2,3-dimethyl benzene 1. X-Ray analysis showed that only the syn conformation is present in the solid state. The conformational preference in solution was evaluated by DFT calculations and experimentally determined by low-temperature NMR experiments. It was found that the anti conformation is the more populated in low-polarity solvents whereas the syn is the favored one in polar solvents.
\end{abstract}

Keywords: Sulfonamides, dynamic NMR, DFT calculations, X-ray crystallography

\section{Introduction}

Hindered aromatic ketones such as 1,4-bis-(mesitoyl)durenes ${ }^{1}$ and 2,3-dimethylnaphthalenes ${ }^{2}$ substituted by two acyl moieties in positions 1,4 have the plane of the carbonyl group nearly orthogonal to that of the aromatic rings and the energy barriers for the aryl-CO bond rotation is high enough as to give rise to two conformational isomers (rotamers), depending as to whether the two carbonyl groups are in an anti or in a syn relationship with respect to the planar core. The corresponding interconversion barriers could be measured by variable-temperature NMR and when the two acyl substituents were sufficiently bulky (e.g. in the case of the $t$-BuCO moieties) it has been even possible to achieve the physical separation of the two rotamers. ${ }^{2}$ We thus considered the possibility that aryl-bis-sulfonamides could exhibit a similar conformational 
behavior, due to the hindered rotation of the Aryl- $\mathrm{NSO}_{2} \mathrm{R}$ bond. At the best of our knowledge, this kind of conformational process has not been investigated in detail, while it could be important in atroposelective reactions where the tosylate can act as a leaving group.

\section{Results and Discussion}

Compound 1 (Scheme 1) was prepared by tosylation and propargylation of 2,3-dimethyl-4-amino aniline in turn prepared by nitration and reduction of 2,3-dimetyl aniline as previously reported. ${ }^{3,4}$ It is worth of mention that the 1,4-tosylation of 2,3-dimethyl-4-amino aniline revealed to be not a trivial task. In fact, after the easy introduction of the first tosyl group, the second tosylation occurred either in 1,4- and in 1,1- position. It appeared that the nucleophilicity of the two nitrogen atoms of the mono tosylated derivative is quite similar. In our opinion this is only apparently surprising when considering that the Electron Donating Group (EDG) $\mathrm{NH}_{2}$ increases the nucleophilicity of the para tosylated nitrogen atom while the Electron Withdrawing Group (EWG) NHTs decreases the nucleophilicity of para $\mathrm{NH}_{2}$ due to conjugation. As an alternative explanation, ${ }^{5}$ the observed similar reactivity of the $\mathrm{NH}_{2}$ and $\mathrm{NHTs}$ group could be due to deprotonation of NHTs group, under the basic reaction conditions (triethylamine was used as base), with increasing of the nitrogen nucleophilicity. However, the 1,3- and 1,4-bistosylation of 1,3-diaminotrimetyl benzene ${ }^{6}$ and 1,4-diaminotetrametyl benzene ${ }^{7}$ is reported to occur without formation of 1,1-bistosylated by-products. Since the deprotonation of NHTs group could be easily operative in these systems as well, while the conjugation between the $\mathrm{NH}_{2}$ and NHTs is prevented by the relative position or/and steric hindrance, the lack 1,1-bistosylated by-products in these reactions strongly supports the first hypothesis. Independently upon the actual reason of the encountered difficulties, 1,4-bis-tosyl amine was isolated in $23 \%$ overall yield after a challenging flash chromatography required to separate the 1,1-bis-tosylated derivative as well as trace amounts of tris- and tetra-tosylated derivatives formed during tosylation.

The following propargylation occurred smoothly on both NHTs groups allowing the isolation of 1 in a $74 \%$ yield (Scheme 1, see the Experimental Section for detailed conditions).



a) $\mathrm{TsCl}, \mathrm{Et}_{3} \mathrm{~N}$, dry $\mathrm{DCM}, 0-25^{\circ} \mathrm{C}$; b) Propargyl bromide, $\mathrm{K}_{2} \mathrm{CO}_{3}$, dry DMF

Scheme 1. Preparation of compound 1. 
The propargyl moiety was conveniently introduced because the $\mathrm{CH}_{2}$ acts as a probe of chirality $^{8}$ that can monitor the conformational motion.

Good single crystals of compound 1 were grown from acetonitrile/methanol solution by slow evaporation. X-ray diffraction analysis showed that the two $\mathrm{SO}_{2}$ moieties are skewed out of the plane of the 2,3-dimethylphenyl ring, the dihedral angles being $93^{\circ}$ and $-94^{\circ}$ (the compound crystallizes in the centrosymmetric $\mathrm{P} 2{ }_{1} / \mathrm{n}$ point group, therefore also the molecule with dihedrals $=-93^{\circ}$ and $+94^{\circ}$ is present in the crystal cell). ${ }^{9}$ The two sulfonyl groups are therefore on the same side of the phenyl ring. While the two $p$-methylphenyl rings are arranged in a parallel disposition pointing in the same direction away from the two methyl groups of the tetrasubstituted central phenyl ring, the two propargyl moieties are arranged in an anti disposition, yielding overall a $C_{1}$ symmetry. Due to the N-S d-p conjugation, ${ }^{10}$ the two carbons and the sulfur bonded to nitrogens lay almost on a plane, being the sum of the three $X-\mathrm{N}-X$ angles close to $360^{\circ}\left(353.0^{\circ}\right.$ and $\left.356.0^{\circ}\right)$.

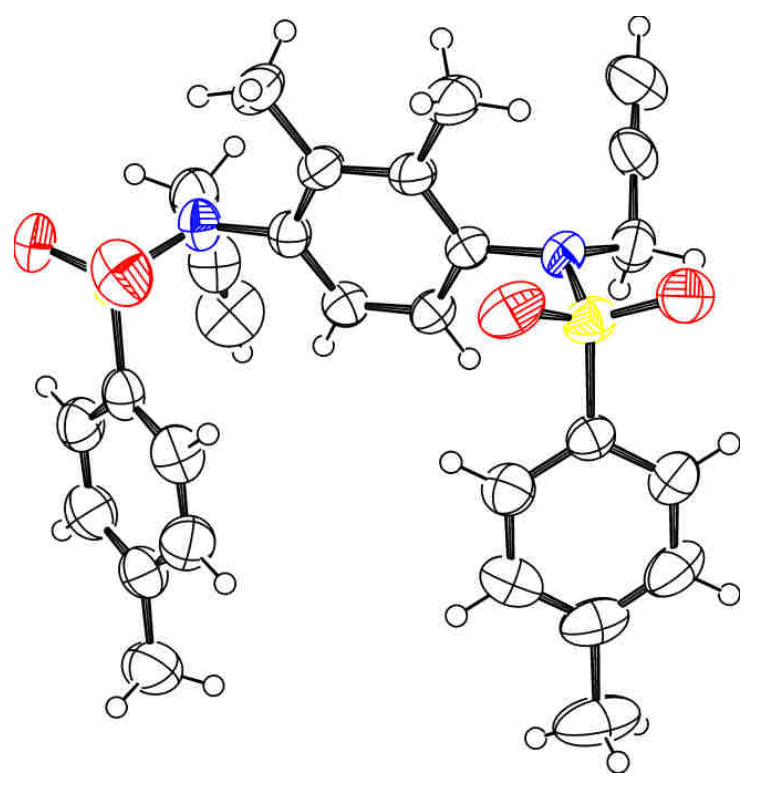

Figure 1. ORTEP structure of compound 1. Ellipsoids drawn at 50\% probability.

Although only one conformation is present in the solid state, two conformational diastereoisomers are expected to exist in solution, provided the relative energy is not exceedingly different. In one conformational diastereoisomer the two $\mathrm{SO}_{2}$ moieties are on the same side with respect to the 2,3-dimethylphenyl plane (i.e. the syn relationship observed in the solid state), and in the second diastereoisomer the two $\mathrm{SO}_{2}$ are on opposite sides (thus an anti relationship). If the $\mathrm{N}-\mathrm{SO}_{2}$ and the $\mathrm{N}-\mathrm{CH}_{2}$ rotational motions are fast, the syn conformation dynamically belongs to the $C_{\mathrm{s}}$ symmetry, while the anti belongs to the $C_{2}$ symmetry group. Nevertheless, if the $\mathrm{N}-\mathrm{SO}_{2}$ rotation is slow in the NMR time scale, both should display diastereotopic hydrogens for the $\mathrm{CH}_{2}$ group because even in the case of the syn conformation the local plane of symmetry of the $\mathrm{CH}_{2}$ does not coincide with the molecular symmetry plane. $^{8}$ 
A Molecular Mechanics (MM) conformational search ${ }^{11}$ localized at least four conformations with similar energy. Two conformations have anti relationship of the sulfonamide moieties, and two have the syn disposition. Within each pair the conformations differ because of the different disposition of the propargyl chain. When optimized by DFT at the B3LYP/6-31+G(d,p) level of theory (Figure 2) the four conformations were validated as energy minima (no imaginary frequencies) and the relative energies are collected in Table 1.

Table 1. B3LYP/6-31+G(d,p) and $\omega \mathrm{B} 97 \mathrm{XD} / 6-31+\mathrm{G}(\mathrm{d}, \mathrm{p})$ calculated energies for compound $\mathbf{1}$ (full optimization, relative values in $\mathrm{kcal} / \mathrm{mol}$ ) in gas phase and with the inclusion of two different solvents (PCM method)

\begin{tabular}{|c|c|c|c|c|c|c|c|c|c|c|c|c|}
\hline \multirow{3}{*}{ Conf } & \multicolumn{6}{|c|}{ B3LYP/6-31+G(d,p) } & \multicolumn{6}{|c|}{$\omega \mathrm{B} 97 \mathrm{XD} / 6-31+\mathrm{G}(\mathrm{d}, \mathrm{p})$} \\
\hline & \multicolumn{2}{|c|}{ Gas Phase } & \multicolumn{2}{|c|}{$\mathrm{CHCl}_{3}$} & \multicolumn{2}{|c|}{ DMSO } & \multicolumn{2}{|c|}{ Gas Phase } & \multicolumn{2}{|c|}{$\mathrm{CHCl}_{3}$} & \multicolumn{2}{|c|}{ DMSO } \\
\hline & $\Delta \mathrm{E}$ & $\Delta \mathrm{H}^{\circ}$ & $\Delta \mathrm{E}$ & $\Delta \mathrm{H}^{\circ}$ & $\Delta \mathrm{E}$ & $\Delta \mathrm{H}^{\circ}$ & $\Delta \mathrm{E}$ & $\Delta \mathrm{H}^{\circ}$ & $\Delta \mathrm{E}$ & $\Delta \mathrm{H}^{\circ}$ & $\Delta \mathrm{E}$ & $\Delta \mathrm{H}^{\circ}$ \\
\hline anti-1 & 0.81 & 0.74 & 0.30 & 0.30 & 0.00 & 0.00 & 1.84 & 2.57 & 1.20 & 1.82 & 1.19 & 2.53 \\
\hline anti-2 & 0.00 & $\mathbf{0 . 0 0}$ & 0.00 & $\mathbf{0 . 0 0}$ & 0.26 & 0.22 & 0.80 & 1.31 & 0.55 & 0.75 & 1.00 & 2.55 \\
\hline syn-1 & 1.29 & 1.29 & 0.64 & 0.68 & 0.68 & 0.36 & 0.74 & 0.74 & 0.01 & 0.00 & 0.00 & 0.00 \\
\hline$s y n-2$ & 0.75 & 0.79 & 0.47 & 0.53 & 0.53 & 0.44 & 0.00 & $\mathbf{0 . 0 0}$ & 0.00 & 0.26 & 0.05 & 0.54 \\
\hline
\end{tabular}

The conformation observed in the solid state corresponds to the syn-1 conformation of Figure 2 suggested by DFT calculations. The syn- 1 conformation was not calculated as the most stable, but the energy differences are small and the conformation observed in the crystal could be the result of a stabilization due to a better lattice packing.

Due to the different relative disposition of the sulfonamide moieties, the dipole moment of the anti and syn conformations is expected to be different. It is thus foreseeable that the polarity of the solvent could influence the relative energies of the conformations at a great extent. For this reason the DFT optimization were run by including different solvents and using the PCM approach. ${ }^{12}$ On raising the dielectric constant of the solvent, the energy difference decreases from $0.79 \mathrm{kcal} / \mathrm{mol}$ (gas phase) to $0.44 \mathrm{kcal} / \mathrm{mol}$ when DMSO was considered. ${ }^{13}$

The results of the B3LYP calculations suggested that both the anti and syn conformation should be populated in solution. However, given the very small energy differences, an assignment of the conformational preference based on calculations will be unreliable. Indeed, when a different functional such as $\omega \mathrm{B} 97 \mathrm{XD}$ (that accounts for long-range interactions and dispersive forces) was employed, the trend was reversed, the syn conformation being always calculated as the more stable, with larger energy differences. The conformation observed in the solid state was calculated to be the most stable when the solvent was introduced in the calculations (Table 1). Within this theoretical level, inclusion of DMSO in the calculations enhanced again the preference for the syn conformation in polar solvents with respect to lowpolarity ones like chloroform. 

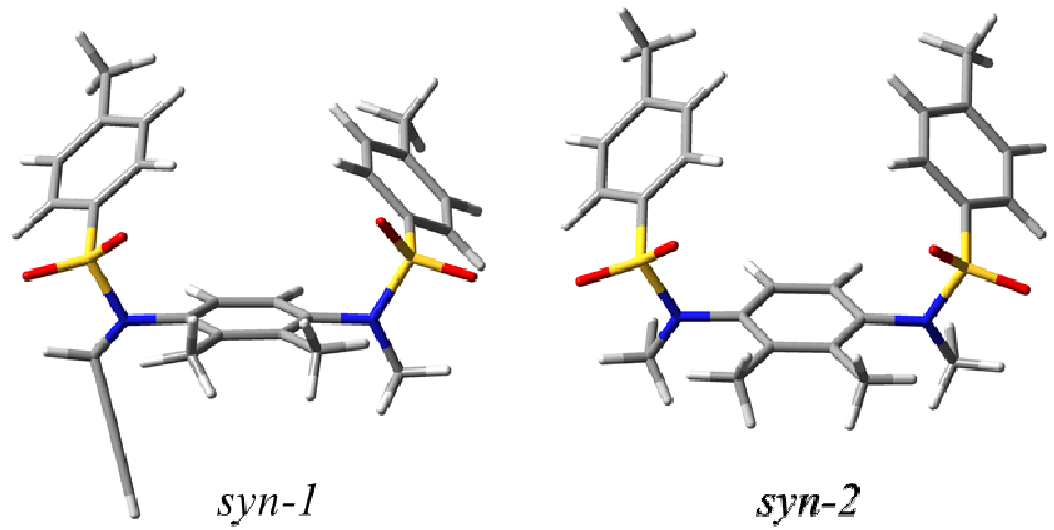

syn-2
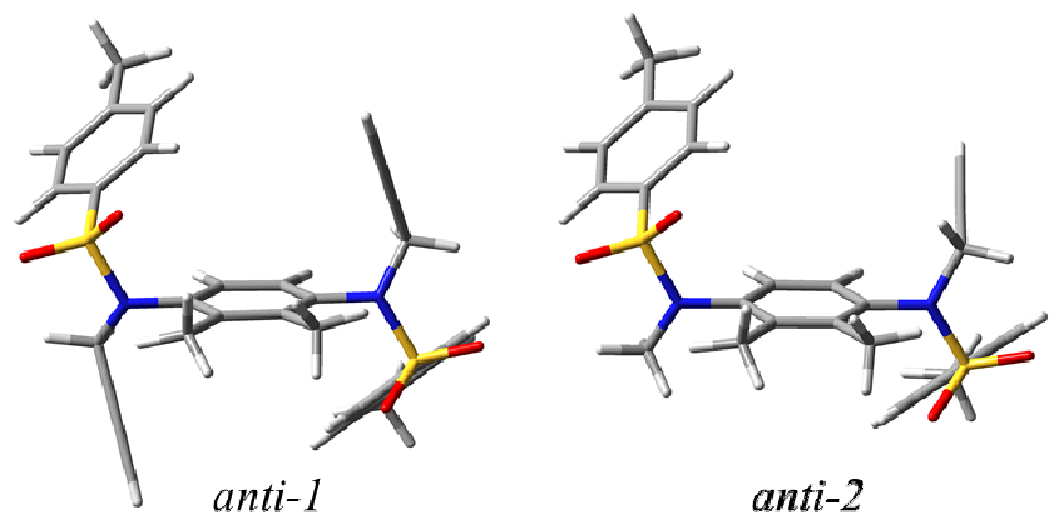

anti-2

Figure 2. Calculated conformations for compound 1. Relative energies are reported in Table 1.

Two transition states were conceived for the rotation of the sulfonamide (Figure 3): the first one has the $\mathrm{SO}_{2}$ pointing towards the $\mathrm{CH}$ of the central ring (TS-1), while the second TS has the $\mathrm{SO}_{2}$ close to the methyls of the central ring (TS-2). When optimized at the B3LYP/6-31+G(d,p) level in the gas phase, both structures were validated as transition states by frequency analysis (a single imaginary frequency corresponding to the rotation of sulfonamide was found). The lower energy transition state was TS-1, i.e. the one with the $\mathrm{SO}_{2}$ group close to the aromatic $\mathrm{CH}$ (20.4 and $21.9 \mathrm{kcal} / \mathrm{mol}$, respectively).

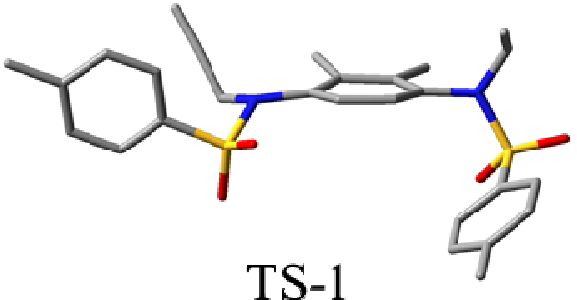

(20.4)

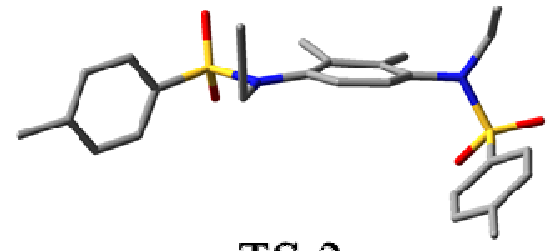

TS-2

(21.9)

Figure 3. The two transition states for Aryl- $\mathrm{NSO}_{2} \mathrm{R}$ rotation. The energies in parenthesis (in $\mathrm{kcal} / \mathrm{mol}, \mathrm{B} 3 \mathrm{LYP} / 6-31+\mathrm{G}(\mathrm{d}, \mathrm{p})$ level) are relative to the lowest energy ground state. 
The ${ }^{1} \mathrm{H}-\mathrm{NMR}$ spectrum of compound $\mathbf{1}$ taken at $+25^{\circ} \mathrm{C}$ in $\mathrm{C}_{2} \mathrm{D}_{2} \mathrm{Cl}_{4}$ showed two sets of signals with 57:43 relative ratio. The aromatic signal of the $\mathrm{CH}$ belonging to the central ring is split into two signals at 6.64 and $6.52 \mathrm{ppm}$, and the signal of the $\mathrm{CH}_{2}$ is split into two $\mathrm{AB}$ systems, with two signals overlapped at $3.83 \mathrm{ppm}$ and the remaining two partially overlapped at $3.52 \mathrm{ppm}$.

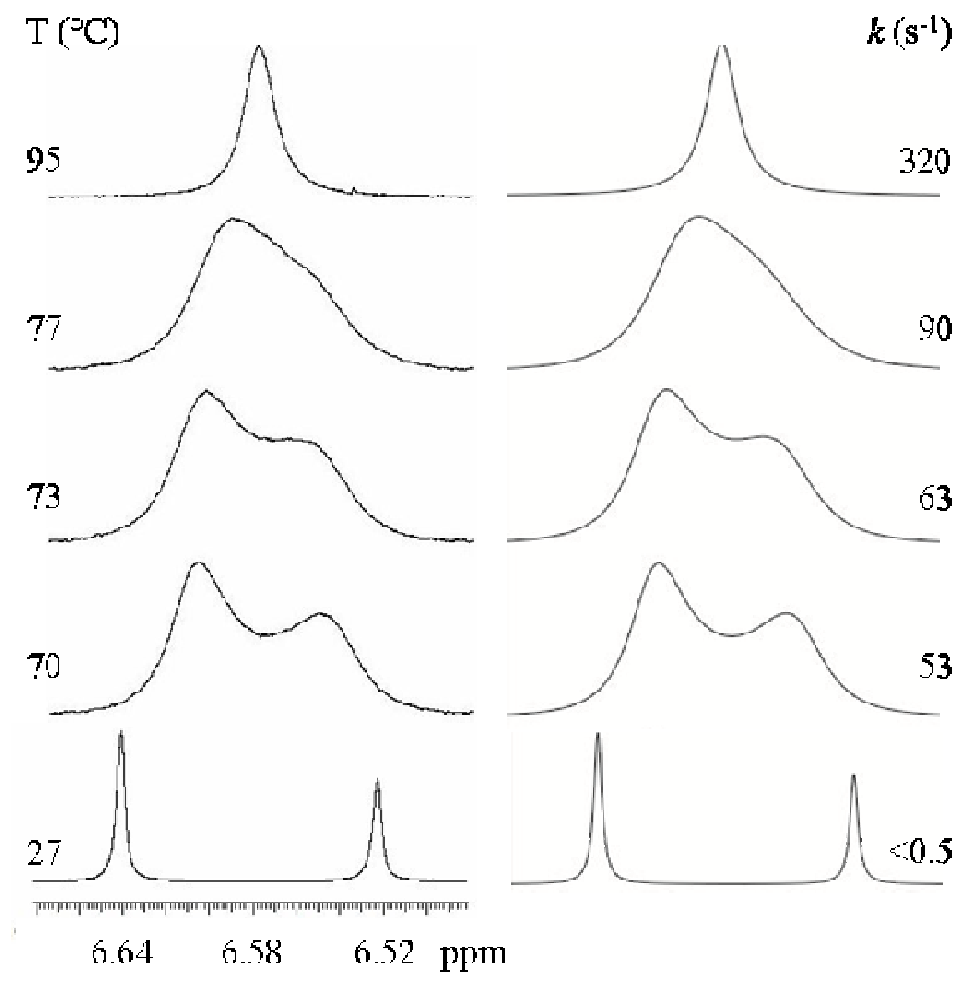

Figure 4. ${ }^{1} \mathrm{H}$ NMR $\left(600 \mathrm{MHz}\right.$ in $\left.\mathrm{C}_{2} \mathrm{D}_{2} \mathrm{Cl}_{4}\right)$ of the aromatic $\mathrm{CH}$ signal of compounds $\mathbf{1}$. On the left are reported the experimental spectra. On the right are reported the lineshape simulations obtained with the indicated rate constants.

The evidence of two sets of signals in the ${ }^{1} \mathrm{H}$ NMR spectrum confirms the existence in solution of the two conformational diastereoisomers, and the diastereotopicity of the hydrogens belonging to the $\mathrm{CH}_{2}$ confirms that the $\mathrm{CH}_{2}$ groups are displaced out of the aromatic plane. On raising the temperature the two signals of the aromatic $\mathrm{CH}$ broaden and reach the coalescence at $+77^{\circ} \mathrm{C}$, eventually yielding a single signal above $+90{ }^{\circ} \mathrm{C}$ (Figure 4). From the rate constants determined by full lineshape simulation an energy barrier of $17.5 \mathrm{kcal} / \mathrm{mol}$ was derived for the conformational process using the Eyring equation ${ }^{14}$. This energy barrier corresponds to the diastereomerization between the syn and the anti conformations. 


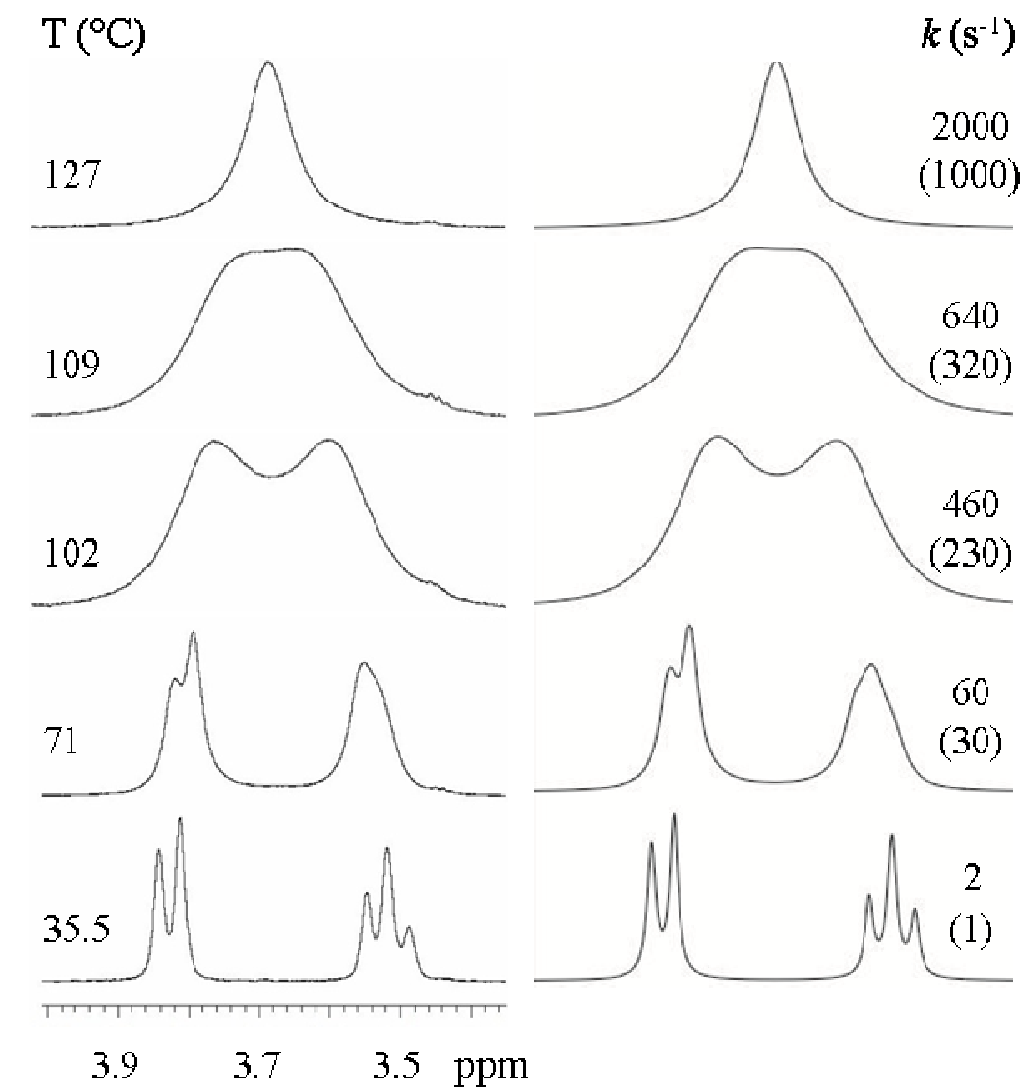

Figure 5. ${ }^{1} \mathrm{H} \mathrm{NMR}\left(600 \mathrm{MHz}\right.$ in $\left.\mathrm{C}_{2} \mathrm{D}_{2} \mathrm{Cl}_{4}\right)$ of the $\mathrm{CH}_{2}$ signal of compounds 1 . On the left are reported the experimental spectra. On the right are shown the lineshape simulations obtained with the indicated rate constants. The rate constants in parenthesis are those for the two-steps racemization/homomerization process (see text for details).

The same behavior was observed for the $\mathrm{CH}_{2}$ signals (Figure 5). The two pairs of signals reach the coalescence at $+109^{\circ} \mathrm{C}$ and yield a single signal above $+120^{\circ} \mathrm{C}$. The line shape simulation of the $\mathrm{CH}_{2}$ signal requires the use of two different rate constants. One accounts for the diastereomerization and it exchanges one $\mathrm{AB}$ system into the other. The second rate constant exchanges the two doublets within each $\mathrm{AB}$ system. The first rate constant has to be identical to that obtained from the simulation of the aromatic $\mathrm{CH}$, while the second one should correspond to $1 / 2$ of the diastereomerization constant, because the racemization of the anti conformation (or homomerization of the syn) is a two-steps pathway that requires the sequential rotation of both the sulfonamide moieties. A satisfactory simulation was indeed obtained using two different rate constants: that for diastereomerization and a halved rate constant accounting for the internal exchange of the AB systems $(18.1 \mathrm{kcal} / \mathrm{mol})$.

The rate constants obtained by the line shape simulations cover a wide range of temperature and allowed us to derive all the activation parameters using both the Arrhenius and Eyring equations (1) and (2), respectively. ${ }^{15}$ 
(1) $\ln (k)=\frac{-E_{a}}{R} \cdot \frac{1}{T}+\ln A$

(2) $\ln \left(\frac{k}{T}\right)=-\frac{\Delta H^{*}}{R} \cdot \frac{1}{T}+\frac{\Delta S^{*}}{R}+\ln \left(\frac{k b}{h}\right)$

From the Arrhenius plot (Figure 6) the activation energy $E_{a}$ was found to be $18.2 \pm 1.0$ $\mathrm{kcal} / \mathrm{mol}$ with $\log \mathrm{A}=13.3 \pm 0.6$ (errors at the $95 \%$ confidence limit). From the Eyring plot the values of activation enthalpy and entropy were derived as $\Delta \mathrm{H}^{\neq}=17.5 \pm 1 \mathrm{kcal} / \mathrm{mol}$ and $\Delta \mathrm{S}^{\neq}=$ $0.0 \pm 2.6$ e.u. As usual in the dynamics of conformational processes, the activation entropy value results to be negligible within the experimental uncertainty. ${ }^{16}$
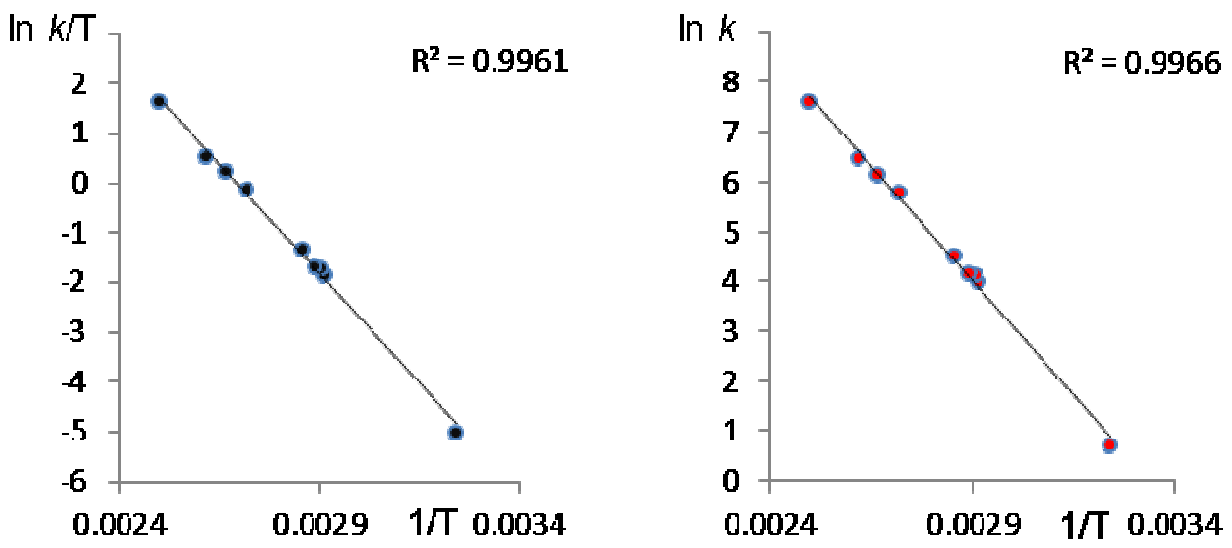

Figure 6. Left: Eyring plot. Right: Arrhenius plot.

As a first attempt to assign the more populated conformation in solution, some different solvents were used because the dipole moment of the syn and anti conformation was calculated to be different. The syn conformation was calculated to be the more polar, and the polarity difference increases when a polar solvent such as DMSO was included in the calculations. $(0.23$ $\mathrm{D}$ in gas phase, $0.65 \mathrm{D}$ in $\mathrm{CHCl}_{3}$ and $1.0 \mathrm{D}$ in $\mathrm{DMSO}$ ). For this reason the ${ }^{1} \mathrm{H}$ spectrum was recorded in DMSO and in a 50:50 v/v DMSO/C $\mathrm{C}_{2} \mathrm{D}_{2} \mathrm{Cl}_{4}$ mixture (Figure 7). When DMSO was used, an inversion of the conformer ratio was observed (left trace of Figure 7, 43:57 ratio). When the solvent mixture was employed, the ratio was 47:53, thus a mismatch due to an inversion of the chemical shift should be ruled out. On this basis, the more populated conformation in lowpolarity solvents should be the anti. 


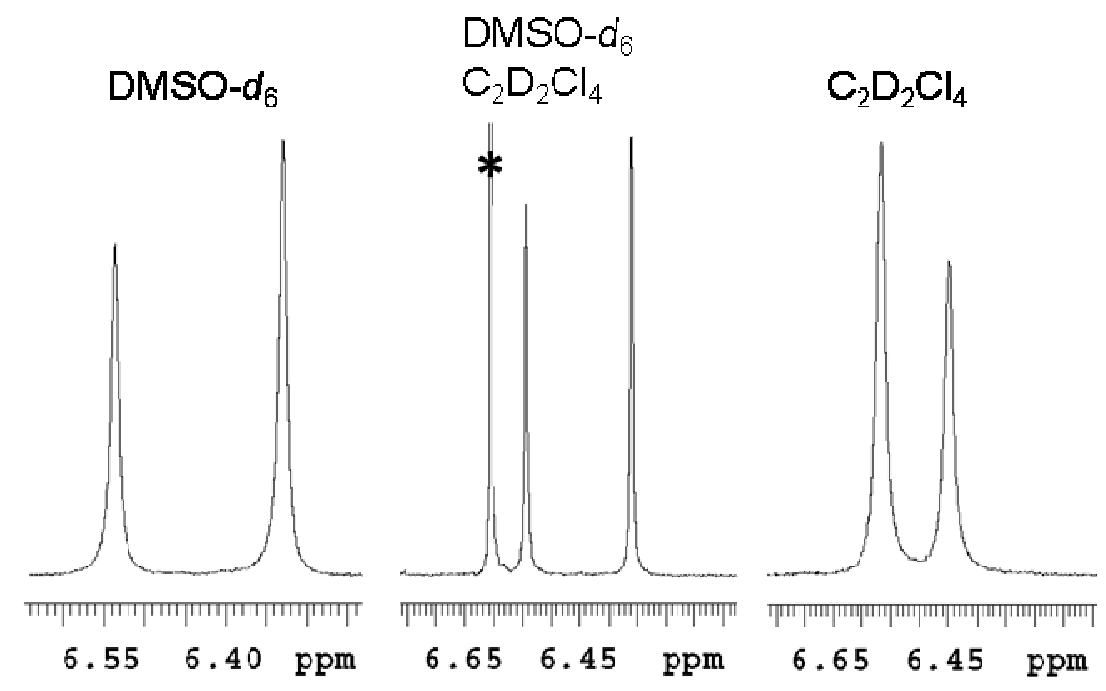

Figure 7. ${ }^{1} \mathrm{H}$ spectra of $\mathbf{1}$ in different solvents. The asterisk indicates the residual signal of $\mathrm{C}_{2} \mathrm{D}_{2} \mathrm{Cl}_{4}$. The relative stability of the conformers is reversed in DMSO with respect to $\mathrm{C}_{2} \mathrm{D}_{2} \mathrm{Cl}_{4}$

Since the X-ray structure was determined on crystals grown from a polar solvent (acetonitrile/methanol), it cannot be excluded that crystals containing the anti conformer could be grown from a low polarity solvent. ${ }^{17}$ However, when single crystals obtained from a chloroform solution were analyzed, they had the very same crystal cell and structure of the others. Thus the preference of the syn conformation in the solid state must be attributed to a more dense crystal lattice, independently of the conformational preference in solution. ${ }^{18}$

To unambiguously assign which conformation is the more populated in solution, a crystal of 1 was dissolved in $\mathrm{CD}_{2} \mathrm{Cl}_{2}$ at $-50{ }^{\circ} \mathrm{C}$ and the spectrum recorded at the same temperature having always kept the sample cooled below this temperature. Since in the solid state only the syn diastereoisomer is present, the aromatic $\mathrm{CH}$ region mainly displays a single signal $(6.31 \mathrm{ppm}$, see Figure 8). When the sample was allowed to warm inside the spectrometer, the line of the second diastereoisomer at lower field $(6.46 \mathrm{ppm})$ increases its intensity, eventually reaching the equilibrium proportion. This behavior confirms that the more populated conformation in lowpolarity solvents is the anti. 

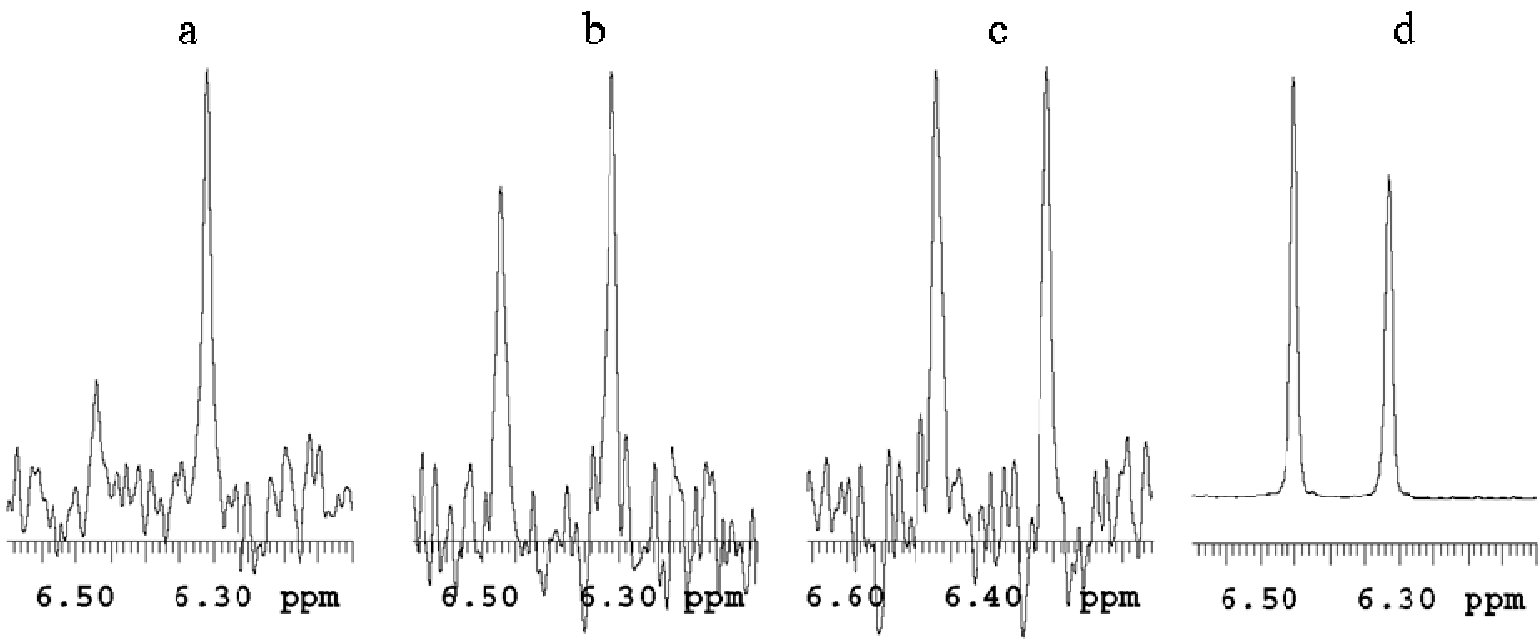

Figure 8. Trace a: $600 \mathrm{MHz}{ }^{1} \mathrm{H}$ spectrum recorded at $-50^{\circ} \mathrm{C}$ on a sample obtained by dissolving a crystal of 1 in $\mathrm{CD}_{2} \mathrm{Cl}_{2}$ at $-50^{\circ} \mathrm{C}$, and kept at this temperature. Trace b: spectrum recorded at $50^{\circ} \mathrm{C}$ after warming the sample at $-30^{\circ} \mathrm{C}$ for $5 \mathrm{~min}$. Trace c: spectrum recorded at $-50^{\circ} \mathrm{C}$ after warming the sample at $-30^{\circ} \mathrm{C}$ for additional $5 \mathrm{~min}$ (total time at $-30{ }^{\circ} \mathrm{C}: 10 \mathrm{~min}$ ). Trace $\mathrm{d}$ : ${ }^{1} \mathrm{H}$ NMR spectrum recorded at $-50^{\circ} \mathrm{C}$ of a sample of $\mathbf{1}$ dissolved at ambient temperature in $\mathrm{CD}_{2} \mathrm{Cl}_{2}$ and then cooled to $-50^{\circ} \mathrm{C}$.

\section{Conclusions}

$\mathrm{N}$-Aryl tosylates display a rather large rotational barrier around the Aryl- $\mathrm{NSO}_{2} \mathrm{R}$ bond, and separate signals due to the syn and anti conformations were observed at ambient temperature when two identical $\mathrm{NSO}_{2} \mathrm{R}$ groups were bound to the same aromatic ring. Due to the different dipole moment, the relative population of the two conformations strongly depends on the solvent, the anti one being the more stable in low polarity solvents. The syn conformation is always the solely populated in the solid state, probably because of a more dense packing.

\section{Experimental Section}

General. Commercial available reagents are used as obtained, unless otherwise stated, from freshly opened container without further purifications. Anhydrous solvents were obtained from Puresolv (Innovative Technology Inc.) apparatus. All the reactions are monitored by TLC on commercially available pre-coated plates (silica gel $60 \mathrm{~F} \mathrm{254)}$ and the products were visualized with acidic vanillin solution. Silica gel 60, 230-400 mesh, is used for column chromatography. Melting points were determined in a capillary tube using a Büchi 510 melting point apparatus and are uncorrected. ${ }^{1} \mathrm{H}$ and ${ }^{13} \mathrm{C}$ NMR spectra were recorded at 200 or 400 and 50 or $100 \mathrm{MHz}$, 
respectively. Chemical shifts $(\delta)$ are expressed in ppm using residual non-deuterated solvent as an internal standard (DMSO, 2.50 for ${ }^{1} \mathrm{H}$ and 39.52 for ${ }^{13} \mathrm{C} ; \mathrm{CDCl}_{3}, 7.26$ for ${ }^{1} \mathrm{H}$ and 77.16 for $\left.{ }^{13} \mathrm{C}\right) .{ }^{19}$ Coupling constants $(J)$ are given in Hertz $(\mathrm{Hz})$.

$N, N^{\prime}$-bis-tosyl-1,4-diamino-2,3-dimethylbenzene. A solution of $p$-toluensulfonyl chloride (280 $\mathrm{mg}, 1.47 \mathrm{mmol})$ in $1 \mathrm{~mL}$ of dry DCM was added dropwise at $0^{\circ} \mathrm{C}$ to a solution of 2,3-dimethyl1,4-diaminobenzene $(100 \mathrm{mg}, 0.73 \mathrm{mmol})$ and dry triethylamine $(162 \mathrm{mg}, 1.6 \mathrm{mmol})$ in $0.5 \mathrm{~mL}$ of dry DCM. The reaction was stirred at $0{ }^{\circ} \mathrm{C}$ under a $\mathrm{N}_{2}$ atmosphere and monitored by TLC (eluent: DCM/AcOEt 20/1) for 2 hours. Then, dry triethylamine $(33 \mathrm{mg}, 0.33 \mathrm{mmol}$ ) and $p$ toluenesulfonyl chloride (57 mg, $0.30 \mathrm{mmol}$ ) were added twice after 4 and $6 \mathrm{~h}$, and the reaction kept at ambient temperature for additional 20 hours. The reaction mixture was diluted with DCM $(40 \mathrm{~mL})$, washed with $10 \%$ aq. $\mathrm{HCl}(3 \times 30 \mathrm{~mL})$ and with water $(2 \times 30 \mathrm{~mL})$. The organic layer was dried over $\mathrm{Na}_{2} \mathrm{SO}_{4}$, filtered and concentrated in vacuum. The crude brown solid obtained (239 mg) was purified by silica gel flash chromatography (eluent: DCM/AcOEt 15/1) to obtain $N, N^{\prime}$ bis-tosyl-1,4-diamine-2,3-dimethylbenzene as a white solid (74 mg, $23 \%$ yield). M.p. 237-238 ${ }^{\circ} \mathrm{C}$; ${ }^{1} \mathrm{H}$ NMR [400 MHz, DMSO-d 6 ]: 1.86 (s, 6H), 2.37 (s, 6H), 6.55 (s, 2H), 7.26-7.40 (m, 4H), 7.40-7.55 (m, 4H), 9.42 (bs, 2H) $\delta ;{ }^{13} \mathrm{C}$ NMR [100.6 MHz, DMSO-d 6 ]: 14.7, 20.8, 124.2, 126.4, 129.2, 132.9, 134.8, 137.2, $142.6 \delta$; IR (KBr pellet): 3273, 1596, 1330, 1159, 1084, $676 \mathrm{~cm}^{-1}$; MS (ESI, negative mode): $m / z$ (int. rel. \%) 443.08 [(M - H) $\left.{ }^{-}, 100\right]$; Elemental analysis for $\mathrm{C}_{22} \mathrm{H}_{24} \mathrm{~N}_{2} \mathrm{O}_{4} \mathrm{~S}_{2}$ : Calcd: C, 59.44\%; H, 5.44\%; N, 6.30. Found: C, 59.73\%; H, 5.19\%; N. 6.63\%.

$N, N$ '-bis-tosyl- $N, N$ '-dipropargyl-1,4-diamine-2,3-dimethylbenzene (1). To a solution of $N, N$ 'bis-tosyl-1,4-diamine-2,3-dimethylbenzene $(90 \mathrm{mg}, 0.2 \mathrm{mmol})$ in dry DMF $(2.5 \mathrm{~mL})$ propargylbromide $(120 \mathrm{mg}, 0.8 \mathrm{mmol})$ and dry $\mathrm{K}_{2} \mathrm{CO}_{3}(113 \mathrm{mg}, 0.8 \mathrm{mmol})$ were added in sequence. The reaction mixture was stirred at $+60{ }^{\circ} \mathrm{C}$ under a positive $\mathrm{N}_{2}$ atmosphere for 24 hours. The reaction was cooled at ambient temperature, diluted with $\mathrm{Et}_{2} \mathrm{O}(100 \mathrm{~mL})$ and washed with $10 \%$ aq. $\mathrm{HCl}(3 \times 30 \mathrm{~mL})$. The acid aqueous phase was extracted with $\mathrm{Et}_{2} \mathrm{O}(2 \times 40 \mathrm{~mL})$. The organic phases were combined, washed with brine $(3 \times 60 \mathrm{~mL})$, dried over $\mathrm{Na}_{2} \mathrm{SO}_{4}$, filtered and concentrated in vacuum. The crude white solid obtained $(98 \mathrm{mg}$ ) was purified by silica gel flash chromatography (eluent: DCM) to obtain $N, N^{\prime}$-bis-tosil- $N, N^{\prime}$-dipropargyl-1,4-diamine-2,3dimethylbenzene 1 as white solid (74 mg, $71 \%$ yield). M. p. $118-120{ }^{\circ} \mathrm{C}(\mathrm{dec}) ;{ }^{1} \mathrm{H}$ NMR $(400$ $\left.\mathrm{MHz}, \mathrm{CDCl}_{3}\right): 2.12(\mathrm{t}, J=2.2 \mathrm{~Hz}, 1 \mathrm{H}), 2.16(\mathrm{t}, J=2.3 \mathrm{~Hz}, 1 \mathrm{H}), 2.26(\mathrm{~s}, 3 \mathrm{H}), 2.32(\mathrm{~s}, 3 \mathrm{H}), 2.42$ (s, 3H), $2.47(\mathrm{~s}, 3 \mathrm{H}), 4.12-4.17(\mathrm{~m}, 1 \mathrm{H}), 4.17-4.23(\mathrm{~m}, 1 \mathrm{H}), 4.48-4.53(\mathrm{~m}, 1 \mathrm{H}), 4.53-4.58(\mathrm{~m}$, $1 \mathrm{H}), 6.55(\mathrm{~s}, 1 \mathrm{H}), 6.59(\mathrm{~s}, 1 \mathrm{H}), 7.14-7.40(\mathrm{~m}, 4 \mathrm{H}), 7.51-7.73(\mathrm{~m}, 4 \mathrm{H}) \delta .{ }^{13} \mathrm{C}$ NMR $(100.6 \mathrm{MHz}$, $\left.\mathrm{CDCl}_{3}\right)$ : 15.9, 16.1, 21.7, 21.8, 41.4, 41.5, 73.8, 73.9, 77.8, 78.0, 126.4, 126.7, 128.3, 128.4, $129.4,129.5,136.2,136.4,138.0,138.2,140.7,140.8,143.8 \delta$ (23 signals of 24 theoretical different carbons due to the diastereoisomeric mixture); IR $\left(\approx 0.03 \mathrm{M}\right.$ in $\left.\mathrm{CDCl}_{3}\right): 3306,2918$, 2262, 1593, 1477, 1348, 1159, $1090 \mathrm{~cm}^{-1}$; MS (ESI, positive mode): $\mathrm{m} / z$ (int. rel. \%) 543.25 $\left[(\mathrm{M}+\mathrm{Na})^{+}, 100\right]$; Elemental analysis for $\mathrm{C}_{28} \mathrm{H}_{28} \mathrm{~N}_{2} \mathrm{O}_{4} \mathrm{~S}_{2}$ : Calcd.: C, 64.59\%; H, 5.42\%; N, 5.38 . Found: C, $64.73 \%$; H, $5.69 \%$; N, 5.22\%. 
Single crystals were obtained from evaporation of an acetonitrile/methanol solution. Cristal structure detail: Molecular formula: $\mathrm{C}_{28} \mathrm{H}_{28} \mathrm{~N}_{2} \mathrm{O}_{4} \mathrm{~S}_{2} ; M_{\mathrm{r}}=520.64$; Monoclinic, space group $\mathrm{P}_{21} / \mathrm{n}$, $a=12.9245(16), b=14.4030(18), c=15.9629(19) \AA, \beta=12.4680(10), V=2746.0(6) \AA^{3}, \mathrm{~T}=$ $298(2) \mathrm{K}, Z=4, \rho_{\mathrm{c}}=1.259 \mathrm{~g} \mathrm{~cm}^{-3}, F(000)=1096$, graphite-monochromated $\mathrm{Mo}_{\mathrm{K \alpha}}$ radiation $(\lambda=$ $0.71073 \AA), \mu\left(\mathrm{Mo}_{\mathrm{K} \alpha}\right)=0.229 \mathrm{~mm}^{-1}$, colourless brick $\left(0.4 \times 0.3 \times 0.15 \mathrm{~mm}^{3}\right)$, empirical absorption correction with SADABS (transmission factors: $0.9664-0.9139$ ), 1440 frames, exposure time $40 \mathrm{~s}, 1.74 \leq \theta \leq 26.42,-16 \leq h \leq 15,-18 \leq k \leq 17,-19 \leq l \leq 19,21271$ reflections collected, 5608 independent reflections $\left(R_{\text {int }}=0.0434\right)$, solution by direct methods (SHELXS97) and subsequent Fourier syntheses, full-matrix least-squares on $F_{\mathrm{o}}{ }^{2}$ (SHELXTL 6.10), hydrogen atoms refined with a riding model, data / restraints / parameters $=5608 / 0 / 329, S\left(F^{2}\right)=1.017$, $R(F)=0.873$ and $w R\left(F^{2}\right)=0.1196$ on all data, $R(F)=0.0461$ and $w R\left(F^{2}\right)=0.1019$ for 3534 reflections with $I>4 \sigma(I)$, weighting scheme $w=1 /\left[\sigma^{2}\left(F_{\mathrm{o}}{ }^{2}\right)+(0.0472 P)^{2}+0.000 P\right]$ where $P=$ $\left(F_{\mathrm{o}}{ }^{2}+2{F_{\mathrm{c}}}^{2}\right) / 3$, largest difference peak and hole 0.199 and -0.327 e $\AA^{-3}$. Crystallographic data (excluding structure factors) for the structure reported in this paper have been deposited with the Cambridge Crystallographic Data Centre as supplementary publication no. CCDC-1029712.

Variable temperature NMR. The variable temperature NMR spectra were obtained by using a flow of dry nitrogen which entered into the NMR probe head by a vacuum-insulated transfer line. The $600 \mathrm{MHz}{ }^{1} \mathrm{H}$ spectra were acquired using a $5 \mathrm{~mm}$ direct probe with a $9000 \mathrm{~Hz}$ spectral width, $2.0 \mu \mathrm{s}$ ( $20^{\circ}$ tip angle) pulse width, $3 \mathrm{~s}$ acquisition time and $1 \mathrm{~s}$ delay time. A shifted sine bell weighting function equal to the acquisition time (i.e., $3 \mathrm{~s}$ ) was applied before the Fourier transformation. Temperature calibrations were performed before the experiments, using a digital thermometer and a $\mathrm{Cu} / \mathrm{Ni}$ thermocouple placed in a NMR tube filled with 1,1,2,2tetrachloroethane. The uncertainty in the temperature measurements can be estimated from the calibration curve as $\pm 1{ }^{\circ} \mathrm{C}$. Line shape simulations were performed using a PC version of the QCPE DNMR6 program. ${ }^{20}$ Electronic superimposition of the original and the simulated spectra enabled the determination of the most reliable rate constants at different temperatures.

Calculations. Ground state optimizations and transition states were obtained by DFT computations performed by the Gaussian 09 rev A.02 series of programs ${ }^{21}$ using standard parameters. The calculations for ground states and transition states employed the B3LYP hybrid HF-DFT functional, ${ }^{22}$ the long-range correlated $\omega \mathrm{B} 97 \mathrm{XD}^{23}$ and the $6-31+\mathrm{G}(\mathrm{d}, \mathrm{p})$ basis set. The analysis of the vibrational frequencies for the optimized structures showed the absence of imaginary frequencies for the ground states, and the presence of one imaginary frequency for each transition state. Visual inspection of the corresponding normal mode ${ }^{24}$ validated the identification of the transition states. If not differently stated, the energy values presented in the results and discussion section derive from total electronic energies. 


\section{Acknowledgements}

The University of Bologna is gratefully acknowledged (RFO-2011 and RFO-2012). Work carried out in the framework of the PRIN2010-2011 project supported by the Italian Ministero dell'Università e della Ricerca (MIUR), PROxi cod. 2010PFLRJR_007.

\section{References}

1. Coluccini, C.; Grilli, S.; Lunazzi, L.; Mazzanti, A. J. Org. Chem. 2003, 68, 7266 - 7273. http://dx.doi.org/10.1021/jo034737t

2. Casarini, D.; Lunazzi, L.; Mazzanti, A. J. Org. Chem. 1998, 63, 4991 - 4995. http://dx.doi.org/10.1021/jo980149h

3. Mousseau, J.J.; Xing, L.; Tang, N.; Cuccia, L. A. Chem. Eur. J. 2009, 15, 10030-10038. http://dx.doi.org/10.1002/chem.200901094

4. Havlík, M.; Král, V.; Kaplánek, R.; Dolensky, B. Org. Lett. 2008, 10, 4767- 4769. http://dx.doi.org/10.1021/ol8018067

5. The authors wish to tank an anonymous referee for this suggestion

6. Adams, R.; Rothstein, M. J. Am. Chem. Soc. 1949, 71, 1620-1621. http://dx.doi.org/10.1021/ja01173a022

7. Avdeenko, A. P.; Yusina, A. L.; Yagupol'skii, L. M. Russ. J. Org. Chem., 2001, 37, 11241129. http://dx.doi.org/10.1023/A:1013140330701

8. a) Jennings, W. B. Chem. Rev. 1975, 75, 307-322. http://dx.doi.org/10.1021/cr60295a003

b) Mislow, K.; Raban, M. Top. Stereochem. 1967, 1, 1-38. http://dx.doi.org/10.1002/9780470147108.ch1

9. Azumaya, I.; Kato, T.; Okamoto, I.; Yamasaki, R.; Tanatani, A.; Yamaguchi, K.; Kagechika, H.; Takayanagi, H. Org. Lett. 2003, 5, 3939-3942. http://dx.doi.org/10.1021/o1035509o

10. Modarresi-Alam, A. R.; Amirazizi, H. A.; Bagheri, H.; Bijanzadeh, H. R.; Kleinpeter, E. J. Org. Chem. 2009, 74, $4740-4749$, and cited references. http://dx.doi.org/10.1021/jo900454a

11. Titan 1.0.5, Wavefunction inc.

12. Tomasi, J.; Mennucci, B.; Cammi, R. Chem. Rev. 2005, 105, 2999-3093. http://dx.doi.org/10.1021/cr9904009

13. Only the best structure for each diastereoisomer was calculated.

14. Eyring, H. J. Chem. Phys 1935, 3, 107 - 115

15. For a full treatment see Sandström, J. in Dynamic NMR Spectroscopy; Sandström, J. Eds.; Academic Press: London, 1982; chapter 7, p 93-123. 
16. For a review see: Casarini, D.; Lunazzi, L.; Mazzanti, A. Eur. J. Org. Chem. 2010, 20352056, and references cited therein. http://dx.doi.org/10.1002/ejoc.200901340

17. Coluccini, C.; Grilli, S.; Lunazzi, L.; Mazzanti, A. J.Org. Chem. 2003, 68, 7266-7273. http://dx.doi.org/10.1021/jo034737t

18. Also in other cases the crystal structure was found to correspond to the less stable conformation in solution. Lunazzi, L.; Mazzanti, A.; Minzoni, M.; Anderson, J. E. Org. Lett. 2005, 7, 1291-1294.

http://dx.doi.org/10.1021/o1050091a

19. Gottlieb, H.E.; Kotlyar, V.; Nudelman, A. J.Org.Chem. 1997, 62, 7512-7515. http://dx.doi.org/10.1021/jo971176v

20. Brown, J. H.; Bushweller, C. H. QCPE Bulletin, 1983, 3, 103-103. A copy of the program is available on request from the authors (A.M.).

21. Gaussian 09, rev A.02. Frisch, M. J.; Trucks, G. W.; Schlegel, H. B.; Scuseria, G. E.; Robb, M. A.; Cheeseman, J. R.; Scalmani, G.; Barone, V.; Mennucci, B.; Petersson, G. A.; Nakatsuji, H.; Caricato, M.; Li, X.; Hratchian, H. P.; Izmaylov, A. F.; Bloino, J.; Zheng, G.; Sonnenberg, J. L.; Hada, M.; Ehara, M.; Toyota, K.; Fukuda, R.; Hasegawa, J.; Ishida, M.; Nakajima, T.; Honda, Y.; Kitao, O.; Nakai, H.; Vreven, T.; Montgomery, Jr., J. A.; Peralta, J. E.; Ogliaro, F.; Bearpark, M.; Heyd, J. J.; Brothers, E.; Kudin, K. N.; Staroverov, V. N.; Kobayashi, R.; Normand, J.; Raghavachari, K.; Rendell, A.; Burant, J. C.; Iyengar, S. S.; Tomasi, J.; Cossi, M.; Rega, N.; Millam, N. J.; Klene, M.; Knox, J. E.; Cross, J. B.; Bakken, V.; Adamo, C.; Jaramillo, J.; Gomperts, R.; Stratmann, R. E.; Yazyev, O.; Austin, A. J.; Cammi, R.; Pomelli, C.; Ochterski, J. W.; Martin, R. L.; Morokuma, K.; Zakrzewski, V. G.; Voth, G. A.; Salvador, P.; Dannenberg, J. J.; Dapprich, S.; Daniels, A. D.; Farkas, O.; Foresman, J. B.; Ortiz, J. V.; Cioslowski, J.; Fox, D. J. Gaussian, Inc., Wallingford CT, 2009.

22. a) Lee, C; Yang, W.; Parr, R. G. Phys. Rev. B 1988, 37, 785-789.

http://dx.doi.org/10.1103/PhysRevB.37.785

b) Becke, A. D. J. Chem. Phys. 1993, 98, 5648-5652.

c) Stephens, P. J.; Devlin, F .J.; Chabalowski, C. F.; Frisch, M. J. J. Phys. Chem. 1994, 98, 11623-11627.

http://dx.doi.org/10.1021/j100096a001

23. Chai, J.-D.; Head-Gordon, M. Phys. Chem. Chem. Phys., 2008, 10, 6615-6620. http://dx.doi.org/10.1039/b810189b

24. GaussView 5.0.9, Gaussian Inc., Wallingford CT, 2009. 